\title{
REVUES
}

\section{INFLUENCE DE L'IRRADIATION SUR LA TENEUR EN VITAMINE A DU LAIT CONCENTRÉ}

\author{
par G. GÉNIN \\ Ingénieur chimiste E. P. C.
}

Le lait concentré constitue aujourd'hui un produit essentiel pour la nourriture de l'homme. Aux Etats-Unis par exemple, où l'emploi des aliments de conserve est pourtant très développé, les ventes de boîtes de lait concentré représentent néanmoins $31 \%$ des ventes totales des produits en conserve. L'importance de ce produit résulte d'ailleurs non seulement de sa grande consommation, mais également des nombreux travaux qui ont été publiés sur sa préparation, ses propriétés et ses qualités nutritives.

Toutefois, jusqu'ici, aucune étude n'avait été faite sur la teneur en vitamine $\mathrm{A}$ du lait concentré et il a fallu attendre les travaux de H. J. Callon et O. F. Hixon, du Laboratoire de technologie des vitamines de Chicago, qui viennent d'être publiés, pour être renseigné sur la teneur en vitamine $\mathrm{A}$ du lait concentré normal et du lait concentré irradié.

Ces auteurs, après avoir examiné les prodụits commerciaux que l'on trouve sur le marché américain, ont pu établir la valeur, en tant que source de vitamine A du lait concentré normal et du lait concentré irradié et mettre ainsi en évidence l'influence éventuelle de l'irradiation par les rayons ultra-violets sur la teneur en vitamine du lait concentré.

On sait que la vitamine $\mathrm{A}$, et plus spécialement sous la forme sous laquelle elle existe dans le lait, est particulièrement sensible à la chaleur et à l'oxydation. Parmi les agents d'oxydation les plus efficaces, il faut citer l'ozone et un auteur a montré, il y a quelques années, que la matière grasse du beurre soumise aux rayons ultraviolets, perd complètement sa vitamine $\mathrm{A}$, cette destruction étant due, non pas aux rayons ultra-violets, mais à l'ozone. C'est d'ailleurs la raison pour laquelle dans tous les procédés d'irradiation du lait concentré on s'est efforcé de réduire au minimum l'influence de l'ozone sur la vitamine A en utilisant des ventilateurs efficaces qui éliminent l'ozone.

Les recherches de CaLLoN et Hixon ont été effēetuées en utilisant comme méthode d'appréciation de la vitamine A la technique décrite dans la Pharmacopée américaine, technique dans laquelle on utilise comme sujets de jeunes rats blanes. Ces rats reçoivent dans leur nourriture une certaine quantité de vitamine $A$ et on suit leur croissance, 
Cette étude a montré que 350 milligrammes de lait concentré irradié assurent la même croissance que $0,5 \mathrm{mgr}$. d'huile de foie de morue de la pharmacopée américaine. Cela revient à dire que le lait irradié essayé contenait 4,28 unités de vitamine A par gramme de lait. Les essais effectués avec le lait concentré normal ont donné des résultats identiques et il semblerait done que le lait normal ou le lait irradié contiennent la même quantité de vitamine A, l'irradiation dans ce cas étant, au point de vue de la vitamine $A$, inutile.

\title{
L'EMPLOI DES RÉCIPIENTS EN CARTON DANS L'INDUSTRIE LAITIËRE
}

\author{
par G. GÉNIN \\ Ingénieur chimiste E. P. C.
}

L'idée de l'emploi des récipients en carton pour la livraison du lait n'est pas nouvelle en elle-même, mais ce n'est que depuis quelques années seulement qu'elle a trouvé des applications nombreuses en France et peut-être plus encore à l'étranger. On aurait paraît-il utilisé 125 millions de récipients aux Etats-Unis, rien que dans l'année 1935. Il semble qu'un domaine nouveau aux possibilités illimitées s'ouvre aux récipients constitués en quelque sorte par de la pulpe de papier rendue imperméable par un revêtementdeparaffine.

On peut dire que c'est depuis 20 ans environ que les essais en vue de l'utilisation des récipients en papier ont pris une certaine importance, mais, toujours pour revenir aux Etats-Unis, ce n'est qu'en 1929 que se créa la première installation à New-York pour les livraisons de lait et de crème dans des récipients en papier. Depuis cette date, l'emploi de ces récipients s'est régulièrement développé et une des plus grandes Sociétés américaines spécialisée dans la fabrication des récipients et boîtes servant à l'emballage a dû, après de nombreuses hésitations, entreprendre à son tour la fabrication des récipients en papier.

Avant cette date, l'emploi de ces récipients était souvent réservé aux livraisons destinées aux commerçants et détaillants. Par exemple, le lait et la crème étaient fournis aux laiteries, aux épiceries et aux pâtisseries dans des récipients en carton. Il y avait plusieurs raisons à cela, en particulier la difficulté et les dépenses qu'entraînaient les multiples échanges des récipients en verre entre fournisseurs et consommateurs. II en résultait des déplacements continuels de camions et on n'avait pu trouver jusqu'alors d'autres récipients suffisamment économiques pour pouvoir être abandonnés et non réutilisés.

Voici d'ailleurs quelques chiffres qui, à ce point de vue, sont très 